\title{
CT Scanning Findings in Clinically Diagnosed Cerebral Palsy
}

\author{
MA WAHED ${ }^{\mathrm{a}}$, MA HOSSAIN ${ }^{\mathrm{b}}$
}

\begin{abstract}
Background: Cerebral Palsy is a non-progressive disorder due to insult in the developing brain.

This causes disorders in muscle tone, posture and movement. Cerebral palsy is usually diagnosed by clinical features. Though risk factors are identified in about $75 \%$ of cases, the etiology remains unclear. Magnetic resonance imaging is the standard method to detect central nervous system abnormalities; but in resource poor areas CT Scanning may be an alternative method to elucidate the underlying Central Nervous System abnormalities.

Objectives: The objective was to detect CT Scanning findings in different types of Cerebral palsies.

Methodology: This was a prospective and cross-sectional study conducted on 525 Children registered at Child Development Center attached to Rangpur Mother and Children Hospital. Cerebral palsy was diagnosed by using an Interview Schedule. During from 1.1.2016 to 31.12.2019 CT scanning of brain was performed purposefully to all children to detect the underlying Central Nervous System abnormalities. The purpose was explained to parents and consent was taken before performing the tests. The children were in sedation during the procedure.

Result: A total of 1800 registered children, 525 (29.10\%) children were suffering from Cerebral Palsy. The male and female ratio was 3:2 and age distribution was $2.6 \pm 1.5$ years.
\end{abstract}

Introduction:

Cerebral Palsy (CP) is a non-progressive disorder due to insult in the developing brain. This causes disorder in muscle tone, posture and movement ${ }^{1,2}$. The global overall prevalence is 2.5 per 1000 populations but there is a variation in incidence, prevalence and epidemiology in different regions. Even the epidemiologic risk factors

a. Prof. Md Abdul Wahed, Chairman, Rangpur Mother and Children Hospital, Rangpur.

b. Prof. Md Altaf Hossain, Prof of Radiology, Rangpur Medical College, Rangpur.

Address of Correspondence: Prof. Md Abdul Wahed, Chairman, Rangpur Mother and Children Hospital, Rangpur. Mobile: 01727569192, E-mail: mawahed.rangpur@gmail.com Received: 22 Oct., 2021

Accepted: 19 Nov., 2021
Seventy nine percent (79.0\%) of children came from poor families. Parental education up to class V was in $65 \%$ cases. Maximum number (63.0\%) of cases was suffering from spastic type of Cerebral Palsy followed by athetoid type (18.3\%) and 7.1\% ataxic type. Among spastics, quadriplegia was present in $68.5 \%$ of cases followed by hemiplegia (18.5\%). Perinatal asphyxia was the commonest (56.1\%) risk factor of Cerebral Palsy. Among all the CTs 116 (22.0\%) were with normal finding and 409 (78.0\%) were with various types of abnormal findings. White Matter Injury was present in 79 (15.0\%) of cases and among these volume loss in periventricular areas with ventricular dilatation and deep white matter damage was common. The next abnormalities were Focal Vascular Insults (9.0\%), Malformations (5.0\%) and Unclassified lesions (4.0\%). Grey Matter Injury was common in spastic type of cerebral palsy but there was much overlapping of abnormal findings and most (66.3\%) insults occurred in perinatal period.

Conclusion: CT scanning of brain is a comparable test to detect the central nervous system abnormalities in resource poor areas. Grey matter injury is the common abnormality in Cerebral palsy but there is much overlapping between CT Scanning findings and clinical diagnosis.

Key words: CT scanning finding, cerebral palsy, resource poor area.

(J Bangladesh Coll Phys Surg 2022; 40: 31-38) DOI: https://doi.org/10.3329/jbcps.v40i1.57055

are changing in the same region over the years ${ }^{3,4,5,6}$. Perinatal asphyxia ${ }^{7,8,9}, \mathrm{LBW}^{10,11,12}$, neonatal sepsis ${ }^{13,14}$, neonatal convulsion ${ }^{15,16,17}$ and neonatal jaundice ${ }^{18}$ are important risk factors. In Bangladesh, $\mathrm{CP}$ is an important cause of disability in children ${ }^{19}$. The diagnosis of $\mathrm{CP}$ is mainly clinical and based on motor impairments, sensations, cognition and behavior. There are four main clinical forms of $\mathrm{CP}$ such as spastic $\mathrm{CP}$, Ataxic $\mathrm{CP}$, dyskinetic $\mathrm{CP}$ and mixed or unspecified form ${ }^{20}$. Neuroimaging in $\mathrm{CP}$ is aimed at looking for the presence and extent of brain injury, with the possibility of determining the lesions, the prognosis and also depicting concurrent or other mimicking lesions.

Cranial Ultrasound (USG) is the first-line imaging modality for newborns and infants before the closure of 
the fontanels. Magnetic Resonance Imaging (MRI) is the gold standard imaging modality in the diagnosis and in the determination of the prognosis of patients suffering from CP. At present situation, this opportunity is available only in large cities of Bangladesh and a small fraction of general population gave accessibility to perform this test. On the other hand, the scope of doing is available in many small cities. It has almost equal power to delineate abnormal structural findings like MRI with cost saving. CT scanning is also the modality of choice in emergency situations and in poorly equipped areas where MRI is not available. In Cameroon, one study ${ }^{21}$ was conducted on computed tomographic finding in $\mathrm{CP}$ in a resource poor area like ours. The Northern region of Bangladesh is relatively resource poor zone. Moreover there is no such study conducted in this zone but CP cases are abundant in this area. Considering this reality the study was conducted to determine and describe the common brain lesions of cerebral palsy in under-five children of CP in the northern zone of Bangladesh where MRI is not still widely available and accessible. Moreover this study may add the value of CT in cases of CP and scope to classify $\mathrm{CP}$ according to structural defect to readers.

\section{Methodology:}

This prospective and cross-sectional study was conducted in Child Development Center (CDC) attached to Rangpur Mother and Children Hospital, Bangladesh from $1^{\text {st }}$ January 2016 to $31^{\text {st }}$ Dec 2019 . A total of 1800 children having different types of disabilities attended this center. Among them 525 children of 1-5 years old were diagnosed as cerebral palsy at first contact using an Interview Schedule. The Interview Schedule used was prepared following standard clinical definitions according to a few epidemiological and review study designs ${ }^{22,23,24}$. This contained three sections - a) history, clinical and developmental examination for immediate diagnosis of $\mathrm{CP}, \mathrm{b}$ ) demographic information, family history, socio-economic history and birth history to get predisposing factors and c) investigations. The mimickers of CP such as neuromuscular disorders, lipid storage diseases, metabolic disorders, cerebral neoplasm and IDD were excluded. Information on perinatal care of mothers and postnatal care of children were also collected from history and medical documents. The schematic process of study is shown in Fig 1 and Fig 2.
All these children underwent a CT scanning of brain. Many of the parents were self-interested to have a CT scanning of brain of their child. In others, there was need of counseling. As CT scanning is associated with radiation exposure, permission was taken from all the parents before performing CT scanning irrespective of self-interest. The CT protocol comprised non-contrast CT scans using a single detector CT scanner (Neusoft Philips 2007). Image acquisition was spiral from the skull base to the vertex, using 3-4 mm slices. The images were reviewed on a work station by one radiologist remaining blind to the clinical information and previous reports. No inter-observer comparison was performed. The CT films in which there was more than one abnormality, the predominant abnormality was considered ignoring the minor one. The previous CT scan, if had, was also ignored. All data were entered into the statistical software SPSS 17.0 version (SPSS Inc. Chicago, USA) and subsequently analyzed by percentage and significance test was done by Chi-square test between exposure (CT Scanning) and outcome (CT scan findings) data in relevant sections. Contingency Tables were prepared from average values and Charts were drawn through MS excel from average extracted data. Though there is no universal agreement on classification of imaging in $\mathrm{CP}$, the findings were grouped according to Australian cohort study as Grey matter injury (GMI), White matter injury (WMI), Focal vascular insults (FVI), Malformations (MAL) and Unclassified (UNC) abnormalities (Fig. 2) ${ }^{25}$.

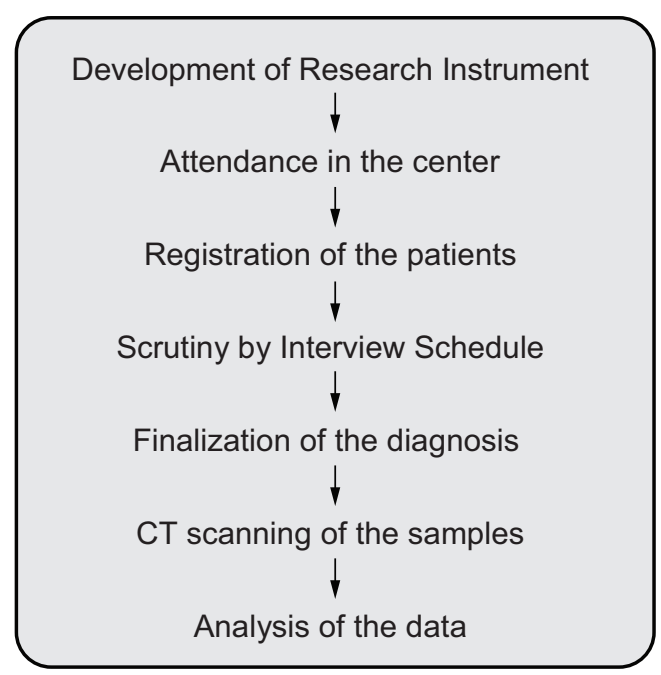

Fig.1: Schematic processes of the study 


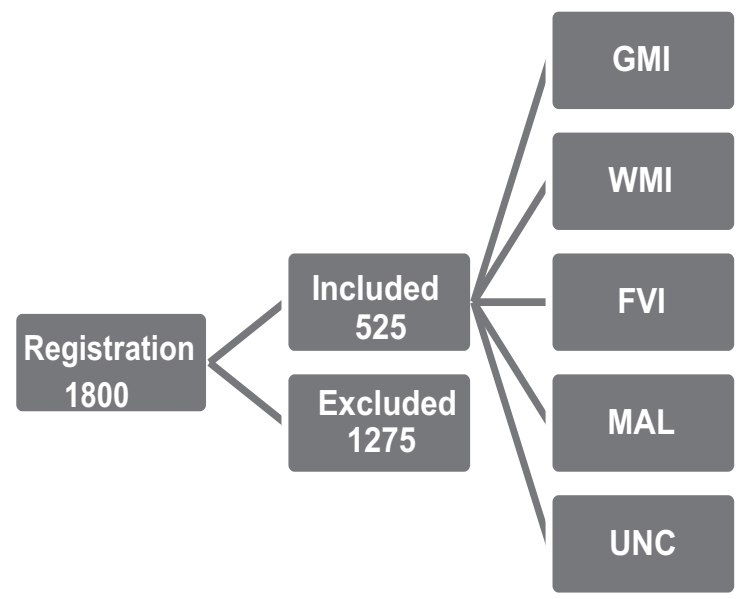

Fig.2: Schematic processes of the study

\section{Results:}

A total of 1800 children were registered and among them 525 (29.1\%) children were suffering from CP. The male and female ratio was $3: 2$ and age distribution was $2.6 \pm 1.5$ years. Seventy nine percent $(79.0 \%)$ children came from poor families. Parental education up to class $\mathrm{V}$ was in $65 \%$ cases (Table 1 ). Maximum number $(63.0 \%$ ) of cases was suffering from spastic type of Cerebral Palsy followed by athetoid type (18.3\%), mixed type (7.6\%), ataxic type (7.1\%) and $4.0 \%$ atonic type (Table 2). Among spastics, quadriplegia was present in $68.5 \%$ of cases followed by hemiplegia in $18.5 \%$ cases (Table 3 ). Perinatal asphyxia was the commonest (56.1\%) risk factor of $\mathrm{CP}$ (Table 4). Among all the CT scan films, $116(22.0 \%)$ were with normal finding and $409(78.0 \%)$ were with various types of abnormal findings (Table 5 and Table 6). Grey Matter Injury was present in $236(45.0 \%)$ of cases and White Matter Injury was present in $79(15.0 \%)$ cases and among these $57(72 \%)$ showed volume loss in periventricular areas with ventricular dilatation, 15 $(19.0 \%)$ had deep white matter damage and $7(9.0 \%)$ had misc. white matter lesions. The next abnormalities were Focal Vascular Insults (9.0\%), Malformations (5.0\%) and Unclassified (4\%) lesions. Grey Matter Injury was common (154/236) in spastic type of cerebral palsy but there was much overlapping of abnormal findings (Table 7) and most (66.3\%) insults occurred in perinatal period (Table 8).
Table-I

Basic characteristics of the samples $(N=525)$

\begin{tabular}{ll} 
Indicators & No $(\%)$ \\
\hline Sex & \\
$\quad$ Male & $350(66.6) \mathrm{M}: \mathrm{F} \mathrm{3:2}$ \\
$\quad$ Female & $175(33.4)$ \\
Age & $0.5 \mathrm{yr}-5 \mathrm{yrs}(\mathrm{SD} 2.6 \pm 1.5)$ \\
Family status & \\
$\quad$ Poor class & $415(79.0)$ \\
$\quad$ Middle class & $92(17.5)$ \\
$\quad$ Higher class & $18(3.5)$ \\
Parental Education & \\
$\quad$ Up to class V & $341(65.0)$ \\
$\quad$ Class VI to X & $147(28.0)$ \\
$\quad$ Above X I class & $37(7.0)$ \\
\hline
\end{tabular}

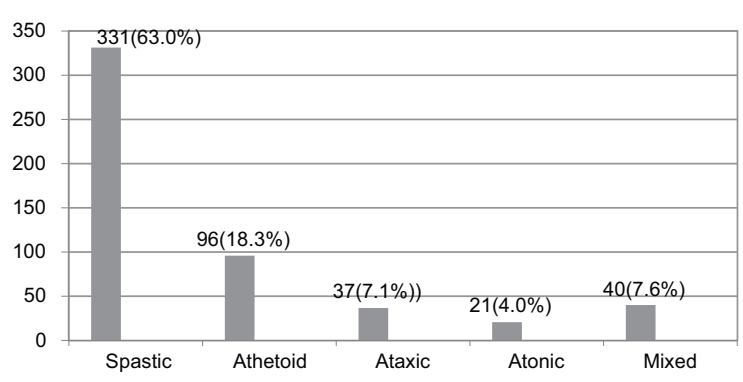

Fig.-3: Types of cerebral palsies $(N=525)$

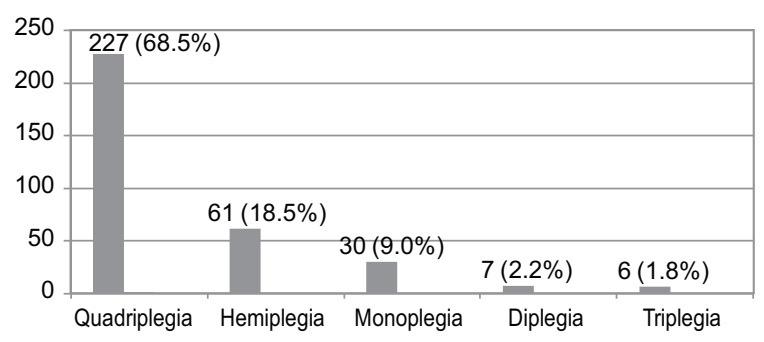

Fig.-4: Sub-types of spastic cerebral palsies $(N=331)$

Table-II

Risk factors of $C P$ in samples $(N=525)$

\begin{tabular}{lll} 
Risk factors & No (\%) & Significance level \\
\hline Pering
\end{tabular}

Perinatal asphyxia (HIE stage $296(56.1)$ z-test $(\mathrm{p}<0.001)$

II and III)

Neonatal seizures (Other than 94 (17.9)

HIE and Sepsis)

LBW 68 (13.1)

Neonatal sepsis $\quad 42(8.0)$

Severe neonatal jaundice $\quad 16(3.1) \quad$ t-test $(\mathrm{p}<0.001)$

Other causes $9(1.8)$

Total $525(100.0)$ 


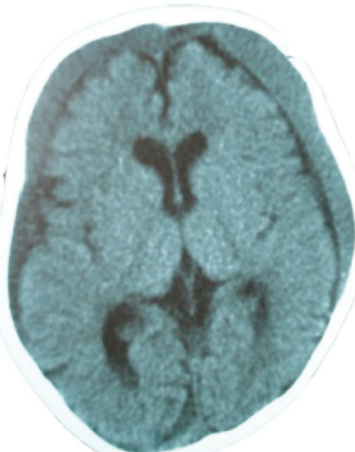

$3 a$

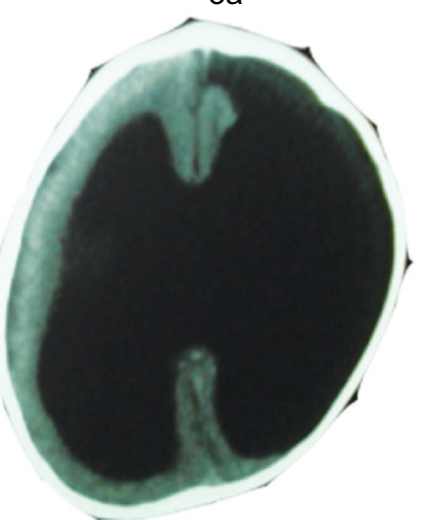

$3 d$

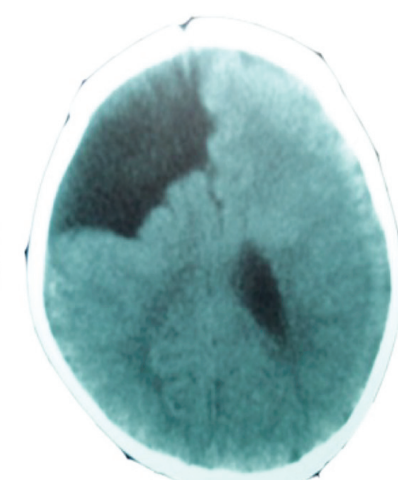

$3 b$

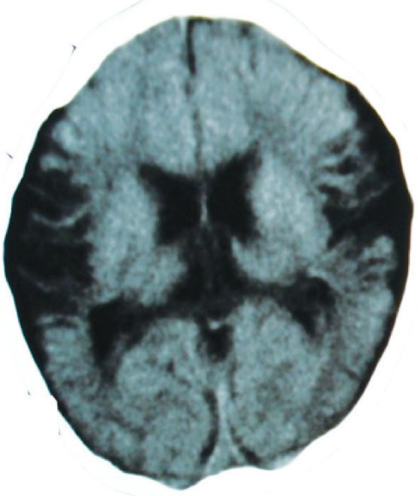

$3 e$

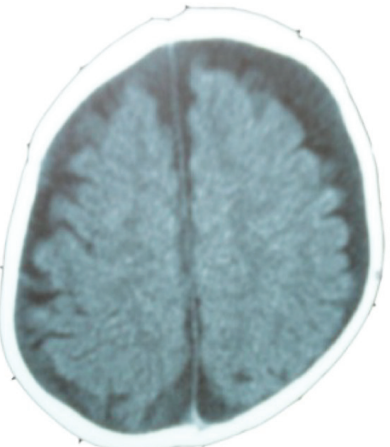

$3 c$

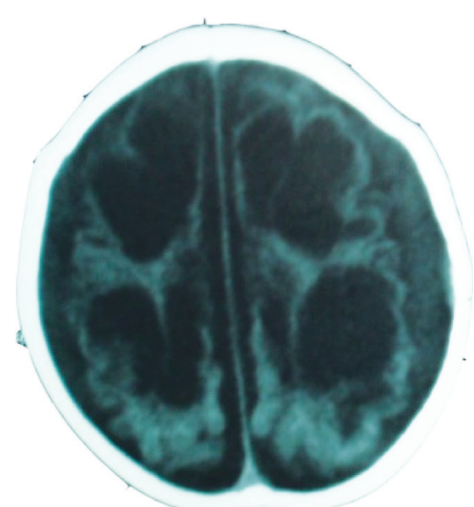

$3 f$

Fig. -5: Photograph of CT Scanning film of some samples; 3a-birth injury (subdural hemorrhage), 3b- grey and white matter infarction, 3c-diffuge cortical atrophy, $3 d$-congenital hydrocephalus, 3e-cortical and sub-cortical atrophy, $3 f$-porencephaly.

\section{Table-III}

\begin{tabular}{lc}
\multicolumn{2}{c}{ Types of abnormal findings $(N=525)$} \\
Pattern* & No $(\%)$ \\
\hline Normal & $116(22.0)$ \\
Grey matter injury & $236(45.0)$ \\
$\quad$ Diffuse cortical atrophy & $146(62.0)$ \\
$\quad$ Focal cortical atrophy & $71(30.0)$ \\
$\quad$ Sub-cortical atrophy & $19(8.0)$ \\
White matter injury & $79(15.0)$ \\
$\quad$ Volume loss in peri-ventricular areas & $57(72.0)$ \\
$\quad$ Deep white matter damage & $15(19.0)$ \\
$\quad$ Spotty/focal white matter damage & $7(9.0)$ \\
Focal vascular insults & $47(9.0)$ \\
Malformations & $26(5.0)$ \\
Unclassified & $21(4.0)$ \\
\hline Total & $525(100.0)$ \\
\hline
\end{tabular}

$* X^{2} p<0.005$

\section{Table-IV}

\begin{tabular}{lccc}
\multicolumn{4}{c}{$\begin{array}{c}\text { Abnormal findings in different types of cerebral } \\
\text { palsies }(N=525)\end{array}$} \\
Type of CP & $\begin{array}{c}\text { Normal } \\
\text { findings }\end{array}$ & $\begin{array}{c}\text { Abnormal } \\
\text { findings* }\end{array}$ & Total \\
\hline Spastic & 78 & 253 & 331 \\
Athetoid & 18 & 78 & 96 \\
Ataxic & 4 & 33 & 37 \\
Atonic & 4 & 17 & 21 \\
Unclassified & 12 & 28 & 40 \\
\hline Total & 116 & 409 & 525 \\
\hline$* \mathrm{X}^{2} \mathrm{p}<0.001$ & & &
\end{tabular}

${ }^{*} \mathrm{X}^{2} \mathrm{p}<0.001$ 
Table-V

Relationship of abnormal findings with cerebral palsy $(N=409)$

\begin{tabular}{lcccccc} 
Abnormalities & Spastic & Athetoid & Ataxic & Atonic & Unclassified & Total \\
\hline GMI & 154 & 35 & 25 & 12 & 10 & 236 \\
WMI & 58 & 19 & - & - & 2 & 79 \\
FVI & 25 & 15 & 5 & - & 2 & 47 \\
MAL & 10 & 5 & 7 & 2 & 2 & 26 \\
UNC & 6 & 4 & 3 & 3 & 5 & 21 \\
\hline Total & 253 & 78 & 40 & 17 & 21 & 409 \\
\hline
\end{tabular}

Table-VI

\begin{tabular}{ll}
\multicolumn{3}{c}{ Assumed origin of lesions } & $(N=409)$ \\
Origin & No $(\%)$ \\
\hline Prenatal & $39(9.5)$ \\
Perinatal & $271(66.3)$ \\
Post natal & $34(8.4)$ \\
Unknown timing & $65(15.8)$ \\
\hline Total & $409(100.0)$ \\
\hline
\end{tabular}

\section{Discussion:}

$\mathrm{CP}$ is the most prevalent neurological disease in children in Bangladesh. There are four types of $\mathrm{CP}$ according to functional impairment such as spastic, ataxic, dystonic and mixed type. But still there is no classification based on structural changes in the brain. This study was conducted to find out the pattern of structural anomalies in the brain of children suffering from $\mathrm{CP}$ which would assist in the classification based on anatomical abnormality. Moreover there many cases of CP where cause is not established by clinical evaluation but CT scanning reveals abnormality which would also augment anatomical classification. Among all the cases of CP, CT scanning of brain was normal in $22.0 \%$ and abnormalities were present in $78.0 \%$ cases. One study in Cameroon, CT scan of brain yielded $90.0 \%$ abnormal findings ${ }^{21}$. Another study revealed $72.5 \%$ abnormal findings in CT scan of brain in children of $\mathrm{CP}^{26}$. Towsley and Colleagues in a population-based study conducted in Quebec, Canada showed 86.9\% abnormal findings in children with $\mathrm{CP}^{27}$. In another study conducted in Victoria, Australia, MRI of $84.0 \%$ children showed abnormal findings ${ }^{28}$. The results of the above studies are comparable to the present study and signify a rationale for choosing CT scans like MRI as a modality to diagnose abnormalities of brain in CP.

Out of 525 samples, 236 (45.0\%) CT films showed Grey matter injury in this study. The Grey matter injuries were diffuse cortical atrophy, focal cortical atrophy and subcortical atrophy. One previous population-based study in Canada showed $14.6 \%$ diffuse Grey matter injury in CT scan films ${ }^{27}$. The higher rate of Grey matter injury in this study may be due to the fact that the birth practice in our country is different from developed countries. Around 65\% deliveries take place at home and perinatal asphyxia is more common. This leads to cortical injury leading to later cortical atrophy. In another crosssectional study conducted in Nigeria by Ibinaiye and Colleagues, cerebral cortical atrophy was present in $46.9 \%$ CT scan films ${ }^{29}$. Another study conducted in North India with almost similar socioeconomic status $47.8 \%$ CT films showed cerebral cortical atrophy ${ }^{30}$. These two studies have almost similar results to our present study.

The White matter injury was present in $79(15.0 \%)$ cases. Among White matter injuries there were volume loss in periventricular areas, deep white matter loss, ventricular dilatation, and cysts in periventricular areas. The above mentioned population-based study ${ }^{27}$ showed $19.2 \%$ White matter injury which is comparable to our study. Australian study ${ }^{25}$ showed $45 \%$ White matter injury and European study ${ }^{31}$ showed $43 \%$ White matter injury in CT scanning in children of CP which are higher than the rate of our study. This is possible in developed countries where the rate of perinatal asphyxia has been declined and the principal risk factors are either 
preterm or preterm-LBW babies. In Sweden, the trend of a birth cohort has shown the lower trend of perinatal asphyxia and higher trend of preterm deliveries in causing $\mathrm{CP}^{32}$.

Different types of Focal vascular injuries were present in $47(9.0 \%)$ cases in this study. Most of the Focal vascular injuries were infarcts, volume loss or porencephalic change in Middle Cerebral Artery territory, venous sinus thrombosis and isolated hemorrhagic lesions. The population-based study by Towsley and colleagues has shown Focal vascular injuries as 11.7\% in their study ${ }^{27}$. Another population-based study in Australia has shown $10.0 \%$ vascular insults among imaging films $\mathrm{s}^{33}$. Our result is almost similar to the above studies.

Different types of Malformations were present in 26 $(5.0 \%)$ films in this study. Malformations were cortical dysplasias, cerebellar dysgenesis, holoprosencephaly, congenital hydrocephalus, agenesis of corpus callosum, microcephaly, and calcified lesions of IU infections. The above mentioned population-based review study ${ }^{33}$ has shown Malformations as $11.0 \%$ and another study ${ }^{27}$ has shown Malformations as $11.3 \%$ in neuroimaging films of children of CP. The explanation of higher values in these studies may be that these studies considered MRI and CT films. The MRI may have a little higher resolution to elucidate the abnormal finding or there may be increased prevalence of malformations in developed countries. In favour of this possibility, one systemic review study has mentioned that MRI has more sensitivity to detect morphological variations, can better discriminate Grey and White matter and can more readily demonstrate malformations ${ }^{34}$. But this variation may be due to sampling patterns which vary from region to region.

In our study, out of 525 children of CP, 21 (4.0\%) CT films yielded unclassified or non-specific lesions. The Australian study ${ }^{28}$ revealed $7.8 \%$ non-specific abnormalities in imaging films. Niemann and Colleagues $^{35}$ in their study have shown $9.8 \%$ miscellaneous abnormalities in CT films and the North Indian study has got $6.4 \%$ miscellaneous findings ${ }^{30}$ which are not vey different from our study.

Spastic cerebral palsy yielded 62\% (253/409) abnormal findings. Taudorf ${ }^{36}$ in cross-sectional study has shown abnormal findings as $67.0 \%$ in children suffering from spastic CP. Ibinaiye ${ }^{29}$ also found that children with spastic cerebral palsy yielded more CT abnormalities. Sadiq $^{37}$ in their cross-sectional study in Kirkuk city showed that yielding of abnormal findings in CT scanning in spastic CP was almost $70.0 \%$. Spastic type of CP also lead to Grey matter injury in $65.0 \%(154 / 236)$ of films. But there was overlapping of abnormalities that is Grey matter injury was also present in other types of $\mathrm{CP}$ in less frequencies. This also indicates to the fact that children of spastic cerebral palsy cause cortical injuries more than other types of cerebral palsy. Ibnaiye ${ }^{29}$ in their study has mentioned that perinatal asphyxia was present among $46.9 \%$ children of cerebral palsy and $46.9 \%$ films also showed cerebral cortical atrophy. On the other hand, Kwong ${ }^{38}$ in their study involving MRI in children with CP have shown that $68.7 \%$ films yielded white matter defects which go against our finding. This may be possible because in developed countries, perinatal asphyxia have been declined and cerebral palsy is contributed by preterm babies where white matter defect is more.

The timing of origin of the brain insult causing cerebral palsy have been categorized into prenatal, perinatal and postnatal sub-groups and the neuropathological abnormalities have linked to gestational and postnatal age of children. Among abnormal findings 9.5\%, 66.3\% and $8.4 \%$ abnormalities were prenatal, perinatal and postnatal origin respectively. History and clinical findings were integrated with nature of abnormal findings. Malformations were linked to prenatal origin. Neonatal intracranial haemorrhage, neonatal encephalopathy, neonatal stroke, neonatal convulsion were linked to perinatal origin. A child having history of sepsis, trauma or convulsion in the postnatal period was linked to postnatal origin. Vascular insults were linked to any of the gestational period according to pregnancy history. There is scientific evidence in support of our assumption that cerebral palsy occurs due to a defect or lesion in the developing brain, which may had its origin in prenatal, perinatal and postnatal period ${ }^{39}$. Neuroimaging contributes to the assessment of timing of brain insults by providing information regarding neuronal migration or glial response. The process of neuronal migration is thought to be complete by the $20^{\text {th }}$ week of gestation. Glial response is thought to begin around the second to third trimester. Migration disorders and glial response abnormalities are therefore 
indicative of lesions occurring in prenatal period and are diagnosed as different types of malformations $\mathrm{s}^{40,41,42 \text {, }}$. There are also several studies in favour of our assumption. Kolawole ${ }^{26}$ in their class II study on multiple defect cerebral palsy, Taudorf ${ }^{36}$ in class II multiple defect cerebral palsy study, Wiklund ${ }^{43}$ in class I study on hemiplegic cerebral palsy and Chen ${ }^{44}$ in a class II study on multiple defect cerebral palsy have shown as prenatal $(16 \%, 11 \%, 44 \%, 33 \%)$, perinatal $(35 \%$, $74 \%, 39 \%, 54 \%)$ and postnatal $(265,15 \%, 00 \%, 13 \%)$ origin respectively in CT films.

Conclusion: CT scanning of brain is a comparable and alternative test with MRI to detect the central nervous system abnormalities in resource poor areas. Grey matter injury is the common abnormality in $\mathrm{CP}$ but there is much overlapping between CT Scanning findings and clinical diagnosis. Further comparative study is needed to generalize this research finding. Still there are several limitations of this study. Abnormal CT scanning findings according to gestational age (preterm and term babies) was not considered like Australian, Canadian and Swedish birth cohort. Abnormal CT scanning findings according to risk factors of $\mathrm{CP}$ were also not done.

\section{References:}

1. Mackieth R, Makenzie I, Polani P. The Little Club Memorandum on terminology and classification of cerebral palsy. Cerebral Palsy Bulletin 1959; 1: 27-35.

2. Rosenbloom L. Diagnosis and management of cerebral palsy. Arch Dis Child 1995; 72: 350-54.

3. Merrick J, Carmeli E. A review on the prevalence of disabilities in Children. The internet journal of Pediatrics and Neonatology 2003; 3(1): 1-24.

4. Impact Foundation Bangladesh. Disability in Bangladesh. www. Impactfoundation.org accessed on 4 April 2009.

5. Lagunju IA, Fatunde OJ. The child with Cerebral Palsy in a developing country - diagnosis and beyound. J Pediatr Neurol 2009; 7(4): 375-89.

6. Pharoah POD, Coocke T, Johnson MA et al. Epidemiology of cerebral palsy in England and Scotland. Arch Dis Fetal Neonatal Ed 1998; 97: F21-F25.

7. Suvanand S, Kapoor SK, Reddaiah VP, Singh U, Sundarum KR. Risk factors for Cerebral Palsy. Ind. J Paed. 1997; 64: 677-685.

8. Bhushon V. Cerebral Palsy and Birth Asphyxia: Myth and Reality. Indian J Pediatr 1994; 61: 49-56.

9. Onyiruka AN. Birth asphyxia in a Mission Hospital in Benin City, Nigeria. Trop J Obs Gynae 2006; 23: 34-39.
10. Cerebral Palsy Square. Risk factors of cerebral palsy. www.neurologychannel.com accessed on 26 April 2011.

11. Blair E, Stanley F. Intrauterine growth and spastic Cerebral Palsy: Association with birth weight for gestational age. Am J Obstet Gynaecol 1997; 182 (1): 229-37.

12. Belonwu RO, Gwarzo GD, Adeleke SI. Cerebral palsy in Kano, Nigeria - a review. Niger Med Apr 2009; 18: 186-9.

13. Iris Lee BA, Jeffrey JN, Phyllis C. The impact of prenatal and neonatal infection on neurodevelopmental outcomes in very preterm infants. J Perinatol 2014; 34(10): 741-47.

14. United Cerebral Palsy Research and Education Foundation. Infection in the newborn as a cause of cerebral palsy. www.ucpresearch.org/fact.sheets accessed on 7 May 2007.

15. Odding E, Roebroeck ME, Stam HJ. The epedimiology of Cerebral Palsy: incidence, impairments and risk factors. Journal Disability and Rehabilitation 2006: 28 (4): 183-191.

16. Hai MSBA, Sarker RN, Akhter A, Biswas P, Kunder GC, Mehedi MT. Determinants of Cerebral Palsy among U-5 Children. Bangladesh Med J 2015; 44(1):3-7.

17. Stanley F, Blair E, Alberman E. Cerebral palsies: Epidemiology and causal pathways. Clinics in developmental medicine no-151, Mackeith Press 2000, London.

18. Wu YW, Kuzuiewcz MW, Wickerimasinghe AC, Walsh EM, Newman TB. Risk of cerebral palsy in infants with total serum bilirubin levels at or above the exchange transfusion threshold: a population-based study. JAMA Pediatr 2015; 169(3): 239-46.

19. Khondaker G, Muhit M. Bangladesh Cerebral Palsy Register: a pilot study to develop a national cerebral palsy register with surveillance of children for CP. BMC Neurol 2015: 15:173.

20. Rosenbaum P, Paneth N, Leviton A, Goldstein M, Bax M, Domiano D et al. A report: the definition and classification of cerebral palsy, April 2006. Dev Med Child Neurol 2007; 49 (Suppl 109): 8-14.

21. Moifo B, Nguefack S, Zeh OF, Oli FA, Tambe J, Gansu FJ et al. Computed tomography findings in cerebral palsy in Yaounde - Cameroon. J. Afr Imag Mçâ 2013; (5) 3: 134-142.

22. Daisy S. Cerebral Palsy. The ORION 2007; 26 (1): 431-433.

23. Paneth N, Hong T, Korzeniewski S. The descriptive epidemiology of cerebral palsy. Clin Perinatol 2006; 33: 251-67.

24. Bax M, Goldstein M, Rosenbaum P, Paneth N, Leviton A, Domiano D et al. Proposed definition and classification of cerebral palsy, April 2005. Dev Med Child Neurol 2005; 47: 571-576.

25. Reid SM, Ditchfield MR, Carlin J, Reddihough DS. Classification of MRI in cerebral palsy: findings from an Australian study and review. Dev Med Child Neurol 2009; 51: 39-45. 
26. Kolawole TM, Patel PJ, Mahdi AH. Computed Tomographic scans in cerebral Palsy. Pediatric Radiology 1989; 20: 23-7.

27. Towsley K, Shevell MI, Dagenais L. Population-based study of neuroimaging findings in children with cerebral palsy. Eur J Paediatr Neurol 2011; 15(1): 29-35.

28. Robinson MN, Peake LJ, Ditchfield MR, Reid SM, Lanigan A, Reddihough DS. Magnetic Resonance Imaging findings in a population-based cohort of children with cerebral palsy. Dev Med Child Neurol 2008; 51: 39-45.

29. Ibanaiye PO, Wammanda DR, Okpe M, Kajogbola GA, Gbagamosi AA, Olarinoye-Akorede S. The role of computerized tomographic scan in the management of children with cerebral palsy. Niger Postgrad Med J 2015; 22(1: 70-4.

30. Aggarwal A, Mittal H, Debath SKR, Rai A. Neuroimaging in cerebral palsy - Report from North India. Iran J Child Neurol 2013; 7(3): 41-46.

31. Bax M, Tydeman C, Flodmark O. Clinical and MRI correlates of cerebral palsy: The European cerebral palsy study group. Journal of the American Medical Association 2006; 296: 602-8.

32. Hagberg B, Hagberg G, Bekung E. Changing panorama of cerebral palsy in Sweden. VIII. Prevalence and origin in the birth year period 1991-94. Acta Pediatr 2001; 90: 271-277.

33. Reid SM, Dagia CD, Ditchfield MR, Carlin JB, Reddihough DS. Population-based studies of brain imaging patterns in cerebral palsy. Dev Med Child Neurol 2014; 56: 222-232.

34. Korzeniewski SJ, Birbeck G, Delano MC, Potchen MJ, Paneth N. A systemic review of neuroimaging in cerebral palsy. J Child Neurol 2008; 23(2): 216-227.
35. Niemann G, Wakat JP, Krageloh-Mann I, Grodd W, Michaelis R. Congenital hemiparesis and periventricular leucomalacia - pathogenic aspects on magnetic-resonanceimaging. Dev Med Child Neurol 1994; 36(11): 943-950.

36. Toudorf K, Melahior JC, Pederson H. CT findings in spastic cerebral palsy: clinical, etiological and prognostic aspects. Neuropediatrics 1984; 15(3): 120-4.

37. Sadiq IM, Nooruldeen SA. Brain computed tomographic findings in children with cerebral palsy. www.researchgate.net/publication accessed on 22.04.2020.

38. Kwong KL, Wong YC, Fong CM, Wong SN, So KT. Magnetic resonance imaging in 122 children with spastic cerebral palsy. Pediatr neurol 2004; 31(3): 172-176.

39. Nelson KB, Ellemberg JH. Epidemiology of cerebral palsy. Adv Neurol 1978; 19: 421-435.

40. Rakie P. Defects of neuronal migration and the pathogenesis of cortical malformations. Prog Brain Res 1988; 73: 15-37.

41. Grant PE, Barkovich AJ. Neuroimaging in CP: issues in pathogenesis and diagnosis. Ment Retard Dev Disabil Res Rev 1997; 3(2): 118-128.

42. Cowan F, Rutherford M, Groenendaal F, Eken P, Mercury E, Bydden GM. Origin and timing of brain lesions in term infants with neonatal encephalopathy. The Lancet 2003; 361: 736-742.

43. Wiklund IM, Uvebrant P, Flodmark O. Computed tomography as an adjunct in etiological analysis of hemiplegic cerebral palsy: class II. Children born at term. Neuropediatrics 1991; 22: 121-128.

44. Chen YH. Correlation between computed tomography of the head and motor development disturbances of children with cerebral palsy. J Jpn Orthopaed Asso 1981; 55(1); 85-99. 